\title{
Modelling pesticide leaching under climate change: parameter vs. climate input uncertainty
}

\author{
K. Steffens ${ }^{1}$, M. Larsbo ${ }^{1}$, J. Moeys ${ }^{1}$, E. Kjellström ${ }^{2}$, N. Jarvis ${ }^{1}$, and E. Lewan ${ }^{1}$ \\ ${ }^{1}$ Department of Soil and Environment, Swedish University of Agricultural Sciences, \\ P.O. Box 7014, 75007 Uppsala, Sweden \\ ${ }^{2}$ Rossby Centre, Swedish Meteorological and Hydrological Institute, 60176 Norrköping, Sweden
}

Correspondence to: K. Steffens (karin.steffens@ @lu.se)

Received: 5 July 2013 - Published in Hydrol. Earth Syst. Sci. Discuss.: 15 August 2013

Revised: 18 December 2013 - Accepted: 30 December 2013 - Published: 6 February 2014

\begin{abstract}
Assessing climate change impacts on pesticide leaching requires careful consideration of different sources of uncertainty. We investigated the uncertainty related to climate scenario input and its importance relative to parameter uncertainty of the pesticide leaching model. The pesticide fate model MACRO was calibrated against a comprehensive one-year field data set for a well-structured clay soil in southwestern Sweden. We obtained an ensemble of 56 acceptable parameter sets that represented the parameter uncertainty. Nine different climate model projections of the regional climate model RCA3 were available as driven by different combinations of global climate models (GCM), greenhouse gas emission scenarios and initial states of the GCM. The future time series of weather data used to drive the MACRO model were generated by scaling a reference climate data set (1970-1999) for an important agricultural production area in south-western Sweden based on monthly change factors for 2070-2099. $30 \mathrm{yr}$ simulations were performed for different combinations of pesticide properties and application seasons. Our analysis showed that both the magnitude and the direction of predicted change in pesticide leaching from present to future depended strongly on the particular climate scenario. The effect of parameter uncertainty was of major importance for simulating absolute pesticide losses, whereas the climate uncertainty was relatively more important for predictions of changes of pesticide losses from present to future. The climate uncertainty should be accounted for by applying an ensemble of different climate scenarios. The aggregated ensemble prediction based on both acceptable parameterizations and different climate scenarios has the potential to provide robust probabilistic estimates of future pesticide losses.
\end{abstract}

\section{Introduction}

The assessment of climate change impacts on the fate and transport of pesticides and other organic pollutants in the environment has been the subject of increased attention and concern in recent years (Bloomfield et al., 2006; Noyes et al., 2009; Delpla et al., 2009; Lamon et al., 2009). Climate change will influence pesticide leaching in a number of ways, which produce both direct and indirect effects. Direct effects arise from changes in temperature and precipitation. Higher temperatures induce faster microbial degradation of pesticides. Sorption is also influenced by changes in temperature, with the nature of the response depending on the characteristics of the chemical compound. Most pesticides sorb to soils with an exothermic reaction for which increased temperature leads to weaker equilibrium sorption (e.g. ten Hulscher and Cornelissen, 1996; Brücher and Bergström, 1997; Shariff and Shareef, 2011) and consequently to higher leaching risks. Higher temperatures imply higher potential evapotranspiration, which might result in increased actual transpiration and thus also changes in percolation and drain flow. In addition, temperature governs processes such as freezing and thawing, as well as the partitioning of precipitation into rainfall and snow. Higher temperatures also enhance diffusion rates, which would tend to increase rates of equilibration of pesticide concentrations between micropores and macropores, and thereby lead to reduced leaching by preferential flow (Jarvis, 1998).

Several studies have demonstrated the impact of precipitation patterns and amounts on pesticide leaching relative to the time of pesticide application (e.g. Capel et al., 2001; 
Holvoet et al., 2007; Nolan et al., 2008; Lewan et al., 2009). In a lysimeter study, Beulke et al. (2002) found an exponential relationship between pesticide losses and total outflow for soils susceptible to preferential flow. Beulke et al. (2007) used the MACRO model (Larsbo et al., 2005) to simulate future pesticide losses in the UK in a climate change perspective. Enhanced losses of pesticides applied in autumn to surface waters were predicted compared to present conditions, most likely due to increased volumes of drain flow and runoff from agricultural fields and higher intensities of individual storm events (Beulke et al., 2007). Variation in soil moisture conditions also influences degradation rates. Increased soil moisture induces faster degradation, unless soil moisture contents are close to saturation (at which point microbial activity and thus degradation may be inhibited). Potentially longer periods of droughts would also reduce degradation and could additionally affect gas diffusion and volatilization of pesticides.

Pesticide leaching can also be indirectly affected by changes in the agroecosystem that are triggered by climate change, such as changes in land-use (e.g. other crop types or more autumn-sown crops), modified pesticide application timings (e.g. more autumn application) or the use of different pesticides against invasive weeds, diseases or pests (Bloomfield et al., 2006; Whitehead et al., 2009). Kattwinkel et al. (2011) focused on these indirect effects of climate change on freshwater ecosystems in Europe and predicted that insecticide applications, runoff and thus ecological risk will significantly increase until the end of the 21st century in large areas of Europe, especially in southern Scandinavia.

Predictions of pesticide leaching under climate change are subject to uncertainties throughout the complete "modelling chain" related to both the climate input data and the pesticide fate model (the impact model; Dubus et al., 2003a; Wilby et al., 2009). Uncertainties in the climate projections mainly arise from the choice of the greenhouse gas emission scenario, the structure and parameterization of the climate models, as well as the initial conditions, which represent the natural variability of the climate system (Hawkins and Sutton, 2009; Wilby et al., 2009; Kjellström et al., 2011). Typically, global climate models (GCMs) provide climate scenarios at a horizontal resolution of $100-300 \mathrm{~km}$. For local and regional applications, this may be too coarse, as such a model cannot account for details of, for instance, land-sea distribution, elevation, or land cover types. Furthermore, relevant processes like mid-latitude low pressure systems are represented in a crude way. Higher resolution GCMs exist (e.g. Zhao et al., 2009), but are expensive to run and therefore not suited for sampling uncertainties related to greenhouse gas emissions, model uncertainty and initial conditions. An alternative way to deal with the coarse resolution in most GCMs is to apply some kind of downscaling in which the original coarse scale data is refined to better represent smaller-scale features. Dynamical downscaling, in which a regional climate model (RCM) is applied to a limited area, is one com- monly used tool in this respect (e.g. Rummukainen, 2010). The choice of procedures to downscale the regional climate projections to even smaller scales (i.e. local or field scales) by applying statistical methods involving observations introduces another source of uncertainty (Wilby et al., 2000; Fowler et al., 2007; Teutschbein et al., 2011). Measurement errors in the observed reference time series as well as the specific choice of reference and future climate periods can contribute to the overall uncertainty related to the downscaling approach (Prudhomme et al., 2010; Ledbetter et al., 2012).

Uncertainties in the modelling chain of climate change impact studies have been addressed in several studies focusing on catchment hydrology (e.g. for river discharges and flood risks; e.g. Graham et al., 2007; Dobler et al., 2012), but such assessments have not yet been performed for pesticide leaching. In a previous study, Steffens et al. (2013) addressed the role of parameter and model structure uncertainty in predictions of pesticide leaching under climate change. However, in their study, only one climate model projection was used to generate future climate conditions.

The aim of this study was, therefore, to assess the impact of uncertainty in climate input data on long-term predictions of pesticide leaching under climate change. The following main questions were explored: (1) does input from different climate model projections result in similar changes of predicted pesticide leaching between present and future climate conditions? (2) Does climate input uncertainty have a larger effect on predicted pesticide losses compared to uncertainties in the parameterization of the pesticide fate model?

To address these issues, $30 \mathrm{yr}$ simulations of pesticide leaching under present and future climate conditions were performed with a set of acceptable parameterizations of the pesticide fate model MACRO obtained from model calibration against field data from a clay soil in south-western Sweden. A nine-member ensemble of regional climate scenarios covering different GCMs, greenhouse gas emission scenarios, and initial conditions of the GCMs (Kjellström et al., 2011) was used to represent the uncertainty in future climate projections.

\section{Material and methods}

\subsection{The MACRO model and its calibration}

The MACRO model (Larsbo et al., 2005), which is used for pesticide registration purposes in the European Union (FOCUS, 2000, 2001), is a physics-based, one-dimensional dualpermeability model for simulating unsaturated-saturated water flow and solute transport in structured, macroporous soils. In the soil matrix, water flow is described by Richards' equation and solute transport by the convection-dispersion equation. Preferential water flow in soil macropores is described by the kinematic wave equation (Germann, 1985). The partitioning of water flow between matrix and macropore systems 
is governed by the infiltration capacity of the soil matrix. The exchange of water and solutes between the two pore domains via diffusion and convection is controlled by an effective diffusion path-length $(d)$, which is a proxy parameter accounting for the geometry of soil macropore structure (Gerke and Van Genuchten, 1996). A complete water balance is simulated: root water uptake is calculated using the model described by Jarvis (1989); flow and transport to drainage systems is calculated by the Hooghoudt equation and seepage potential theory. Pesticide degradation is described by first-order kinetics, with the rate coefficient given as a function of soil temperature, according to the Arrhenius equation (Boesten and Van der Linden, 1991) and moisture content, following a modified Walker function (Walker, 1974). In this study, sorption is described with a linear isotherm, although MACRO can deal with non-linear Freundlich sorption isotherms. We used an extended version of MACRO5.2 that describes sorption and diffusion as temperature-dependent processes (see Steffens et al., 2013). Temperature-dependent diffusion is implemented based on the relationship between the diffusion coefficient of a specific chemical and the viscosity at reference temperature and the actual temperature. The effect of temperature on sorption is simulated according to the van't Hoff equation for linear equilibrium sorption with a constant sorption enthalpy.

The model was calibrated against a comprehensive data set from a field plot experiment performed at Lanna, in south-western Sweden $\left(58^{\circ} 21^{\prime} \mathrm{N}, 13^{\circ} 08^{\prime} \mathrm{E}\right)$, using the generalized likelihood uncertainty estimation method (GLUE, Beven and Binley, 1992) according to the procedure described in Steffens et al. (2013). Soil water content at different depths in the soil profile and drain discharge were measured, as well as the concentrations of the non-reactive tracer bromide and the mobile herbicide bentazone in both soil and drainage flow, for a period of 14 months following application of the pesticide in October 1994. This field experiment is described in detail in Larsson and Jarvis (1999). The soil at Lanna is a silty clay (Typic Eutrochrept, USDA, see Table 1) that has been under no-tillage practice since 1988. Thus, it represents a "worst-case soil" in terms of pesticide leaching via preferential flow to drains, since it has a strongly developed and stable aggregate structure and abundant earthworm biopores.

Based on previous studies, the following parameters are known to be sensitive and uncertain (Boesten, 1991; Dubus et al., 2003b; Dubus and Brown, 2002; Larsbo and Jarvis, $2005)$ and were therefore included in the calibration procedure: saturated matrix hydraulic conductivity $\left(K_{b}\right)$, diffusion path-length $(d)$, degradation rate coefficient $(\mu)^{1}$, and the soil organic carbon partitioning coefficient $\left(K_{\mathrm{oc}}\right)$. Each of these parameters was calibrated separately for both the topsoil (0-

\footnotetext{
$1 \mu$ was used as input to the model, but we sampled from a distribution of degradation half-life time values (DT50), which is the reciprocal of $\mu$ multiplied by $\ln (2)$.
}

Table 1. Clay, sand and organic carbon content of the field site in Lanna (from Bergström et al., 1994). The upper horizon is considered to be topsoil and the rest of the soil profile is considered to be subsoil.

\begin{tabular}{lccc}
\hline $\begin{array}{l}\text { Depth } \\
{[\mathrm{cm}]}\end{array}$ & $\begin{array}{c}\text { Clay } \\
(<2 \mu \mathrm{m})[\%]\end{array}$ & $\begin{array}{c}\text { Sand } \\
(>60 \mu \mathrm{m})[\%]\end{array}$ & $\begin{array}{c}\text { Organic } \\
\text { carbon }[\%]\end{array}$ \\
\hline $0-30$ & 46.5 & 7.3 & 2.0 \\
$30-60$ & 56.1 & 3.3 & 0.8 \\
$60-100$ & 60.6 & 2.0 & 0.3 \\
$100-175$ & 66.6 & 2.9 & 0.2 \\
\hline
\end{tabular}

$30 \mathrm{~cm}$ ) and subsoil (below $30 \mathrm{~cm}$ ). All other parameters were set to the values in Steffens et al. (2013). Based on the previous results of Steffens et al. (2013), we narrowed the initial prior uncertainty ranges of $K_{b}$ in topsoil and subsoil, as well as $\mu$ and $K_{\text {oc }}$ in the topsoil to increase the sampling density, while reducing the number of simulations. We sampled 40000 parameter combinations according to a latin hyper-cube sampling scheme from uniform prior distributions. The calibration model runs were initialized with measured soil water contents and driven by on-site measurements of precipitation and other meteorological variables. Acceptable parameter sets were defined as simulations that gave positive model efficiencies (Nash and Sutcliffe, 1970) for all six available types of measurements.

Acceptable parameter sets are often weighted according to their performance in the calibration procedure (Beven, 2006). However, we gave equal weights to all acceptable parameterizations, since tests showed that the effects of weighting (either by averaging or multiplying the six model efficiencies) on cumulative distribution functions of predicted leaching were negligible.

\subsection{Predictions for present and future climate conditions}

\subsubsection{Climate input data}

\section{Reference climate data}

The weather station at Såtenäs $\left(58^{\circ} 26^{\prime} \mathrm{N}, 12^{\circ} 41^{\prime} \mathrm{E}\right)$ was used as a representative station for the region around the field site in Lanna (region 5a; Johnsson et al., 2008). Data from this station were used to represent the present climate of the $30 \mathrm{yr}$ period between 1970 and 1999. Daily time series of average temperature, solar radiation, wind speed and vapour pressure deficit are required by MACRO to internally calculate potential evapotranspiration using the Penman-Monteith equation (Jarvis, 1994). Daily precipitation data were disaggregated to hourly data according to the method by Olsson (1998) and used as driving data for MACRO. 
Table 2. Summary of the different climate model projections used in this study (see also Kjellström et al., 2011). RCM stands for regional climate model, GCM for global climate model, and SRES stands for the greenhouse gas emission scenarios as defined in the special report on emission scenarios.

\begin{tabular}{llllcl}
\hline $\begin{array}{l}\text { Climate } \\
\text { scenario }\end{array}$ & RCM & GCM & SRES & Initial state & Reference for GCM \\
\hline CS1 & RCA3 & BCM & A1B & - & Bleck et al. (1992); Déqué et al. (1994) \\
CS2 & RCA3 & CCSM3 & A1B & - & Collins et al. (2006) \\
CS3 & RCA3 & HadCM3Q0 & A1B & - & Gordon et al. (2000) \\
CS4 & RCA3 & IPSL & A1B & - & Hourdin et al. (2006) \\
CS5 & RCA3 & ECHAM5 & A1B & r1 & Roeckner et al. (2006); Jungclaus et al. (2006) \\
CS6 & RCA3 & ECHAM5 & A1B & r2 & Roeckner et al. (2006); Jungclaus et al. (2006) \\
CS7 & RCA3 & ECHAM5 & A1B & r3 & Roeckner et al. (2006); Jungclaus et al. (2006) \\
CS8 & RCA3 & ECHAM5 & B1 & r1 & Roeckner et al. (2006); Jungclaus et al. (2006) \\
CS9 & RCA3 & ECHAM5 & A2 & r1 & Roeckner et al. (2006); Jungclaus et al. (2006) \\
\hline
\end{tabular}

\section{Climate scenarios}

Outputs from nine different climate model projections dynamically downscaled by the same RCM (called RCA3, Samuelsson et al., 2011) were used to derive future time series of climate data. This ensemble of RCM projections covered different combinations of GCMs, greenhouse gas emission scenarios, and initial states of the GCMs (Table 2). The output of each of these individual climate modelling chains is referred to as a climate scenario in the following. From the grids of the RCM projections, only the grid cell covering the study site was used.

\section{Delta change method}

Average monthly change factors (Wilby et al., 2009; Anandhi et al., 2011) were derived by comparing present (1970-1999) and future climate periods (2070-2099) as projected by each member of the ensemble of climate scenarios. These monthly change factors were applied to systematically change the observed time series in order to generate a future time series. Additive change factors were used in the case of temperature and solar radiation. To get smooth changes, we used the calculated change factors for the 15 th of each month and interpolated linearly between the months to get a separate change factor for each day. For precipitation, multiplicative change factors (without interpolation) were applied. Since projected changes in wind speed towards the end of this century do not show systematic patterns (Kjellström et al., 2011), we kept the wind speed unchanged. Relative humidity was also kept the same as in the reference scenario. The rationale for this is that both observations and model results show that relative humidity would broadly be maintained in a changing climate, as changes in water vapour are governed by changes in temperature following the Clausius-Clapeyron relation (Bengtsson, 2010).

The monthly change factors for temperature and precipitation are shown for the selected climate scenarios in Fig. 1. A larger ensemble could potentially show a larger spread of change factors. We compared the spread in our scenarios to an ensemble of more than 20 GCMs taken from CMIP3 (Coupled Model Intercomparison Project, Phase 3, cf. Christensen et al., 2007), for which Lind and Kjellström (2008) calculated monthly change factors for southern Sweden, comparing the period 2071-2100 with 1961-1990. Our RCA3-ensemble for south-western Sweden captures the seasonal signatures of the changes in temperature and precipitation well and covers a large part of the spread in precipitation changes; however, it shows a narrower range of projected increases in temperature than the GCM ensemble (see Fig. 1).

The change factor method assumes a constant bias over time and does not take into account changes in frequency distributions of the climate variables, which might be important, especially for precipitation. We still considered the method adequate for our study because (a) it represents realistic climatic conditions for the location of interest, including daily rainfall amounts and temporal patterns, as it is based on observations; (b) it removes the biases within the different models, which is an advantage when using multiple climate models (Ledbetter et al., 2012); (c) other types of methods for downscaling from the regional to local scale would introduce additional uncertainties (Chen et al., 2011); (d) we keep a consistent relationship between downscaled precipitation and the variables needed to calculate potential evapotranspiration, which is not the case with most (simple) statistical downscaling methods (Fowler et al., 2007); (e) the method is simple and the interpretation of the results is clearer if only the magnitude and not the frequency of extreme events is changed.

\subsubsection{Pesticide application scenarios}

Predictions of pesticide leaching were performed with all nine climate scenarios for three hypothetical compounds, which were defined by multiplying the calibrated $K_{\mathrm{oc}}$ values for bentazone by a factor of 1,10 , and 50 to represent weakly, moderately, and strongly sorbed pesticides, respectively (see 
Table 3. Results from the statistical analysis performed for the pesticide application scenarios of the different hypothetical compounds. $F_{\mathrm{PU}}$ denotes the ratio of variance within the climate input to the total variance in $\%$ for the absolute losses (abs) and for the predicted change ( $\Delta$ ). The given $p$ values are the results from the Kruskal-Wallis $(\mathrm{KW})$ test, a non-parametric analysis of variance. Kendall's $W$ test renders values between 0 and 1 for no agreement and full agreement, respectively, between the ranks for pesticide losses as simulated with the different climate scenarios over the range of acceptable parameterizations of the pesticide fate model.

\begin{tabular}{llllcclcc}
\hline \multicolumn{3}{c}{ Pesticide } & & \multicolumn{4}{c}{ Statistical tests } \\
\cline { 1 - 4 } \cline { 5 - 7 } Scenario & Sorption & Application & & $F_{\mathrm{PU}_{\text {abs }}}$ & $F_{\mathrm{PU}_{\Delta}}$ & $p$ value $(\mathrm{KW})$ & Kendall's $W$ \\
\hline WsSpr & weak & spring & & 92.0 & 54.9 & 0.790 & 0.880 \\
WsAut & weak & autumn & & 87.7 & 35.8 & 0.741 & 0.851 \\
MsSpr & moderate & spring & & 93.9 & 53.3 & 0.258 & 0.859 \\
MsAut & moderate & autumn & & 85.6 & 53.5 & $<0.0005$ & 0.873 \\
SsSpr & strong & spring & & 98.4 & 64.1 & 0.110 & 0.882 \\
SsAut & strong & autumn & & 97.3 & 69.3 & $<0.0005$ & 0.912 \\
\hline
\end{tabular}

Table 3). We used the same sorption enthalpy for all three hypothetical compounds $\left(-30 \mathrm{~kJ} \mathrm{~mol}^{-1}\right)$. Leaching of these hypothetical pesticides was simulated for spring and autumn applications under present and future climate conditions with the same yearly dose of $0.45 \mathrm{~kg} \mathrm{ha}^{-1}$. Each unique combination of hypothetical pesticide and application period is hereafter referred to as a pesticide application scenario. In all these pesticide application scenarios, the crop was winter wheat. Pesticides were applied between 1 and 16 May and between 29 September and 15 October for spring and autumn scenarios, respectively, based on the current agricultural practice in the studied region (Graaf et al., 2010, 2011). The application date in each year was chosen randomly among all days with less than $2 \mathrm{~mm}$ of rain. We chose the same application dates for the present time series and all climate scenarios in order to avoid an additional source of uncertainty. In order to ascertain that the choice of individual application dates did not significantly affect the overall results, two sets of simulations were conducted with different realizations of pesticide application days. The differences in the cumulative distribution functions for pesticide leaching between these two sets of simulations were negligible. This suggests that a $30 \mathrm{yr}$ simulation period was sufficient to account for the effects on leaching of year-to-year variations in weather conditions in relation to application timing.

In order to generate appropriate initial conditions, a sixyear spin-up period was run preceding the $30 \mathrm{yr}$ simulations, as is commonly done in simulations for pesticide registration purposes (FOCUS, 2000, 2001). Thus, simulations were run for $36 \mathrm{yr}$, of which the first six years (the spin-up period) were excluded from the analysis.

\subsubsection{Presentation of results}

As target output variable, we focused on the accumulated pesticide loss to drains for the $30 \mathrm{yr}$ period expressed as a percentage of the total amount of pesticide applied during that period. Apart from presenting the actual losses simulated with the pesticide fate model, we calculated the differ- ence in simulated pesticide losses between present and future scenarios separately for each parameter set, climate scenario and pesticide application scenario. The latter results are displayed as changes in total pesticide losses, for which the absolute differences are given in the same unit as the actual losses.

\subsubsection{Statistical analysis}

The importance of climate input uncertainty relative to parameter uncertainty of the pesticide fate model was evaluated using three statistical indices and tests. Each test was conducted separately for each pesticide application scenario and for both absolute pesticide losses and changes in pesticide losses from present to future.

The fraction of the variance in predicted pesticide leaching losses explained by the parameter uncertainty $\left(F_{\mathrm{PU}}\right)$ in relation to the total variance, which included both parameter and climate input uncertainty, was calculated as

$$
F_{\mathrm{PU}}=100\left(\frac{\sum_{i=1}^{k} \sum_{j=1}^{n}\left(y_{i j}-\bar{y}_{i}\right)^{2}}{\sum_{i=1}^{k} \sum_{j=1}^{n}\left(y_{i j}-\bar{y}\right)^{2}}\right),
$$

where $y_{i j}$ are the predictions of the $j$ th parameter set in response to the $i$ th climate scenario, $\bar{y}_{i}$ denotes the average prediction in response to the climate scenario $i$, and $\bar{y}$ the overall average prediction for all parameter sets and climate scenarios. The closer $F_{\mathrm{PU}}$ is to 100 , the larger is the contribution of parameter uncertainty to the total uncertainty of the predictions of pesticide losses and changes in pesticide losses, respectively.

In addition, we performed the Kruskal-Wallis test, a nonparametric analysis of variance, to test whether the ensemble mean output of the nine different climate scenarios (i.e. $\bar{y}_{j}$, following the syntax in Eq. 1) were significantly different between the acceptable parameter sets. A non-significant result would suggest that the parameterizations are very similar in their predictions of average pesticide losses based on the nine-member ensemble of climate scenarios. 


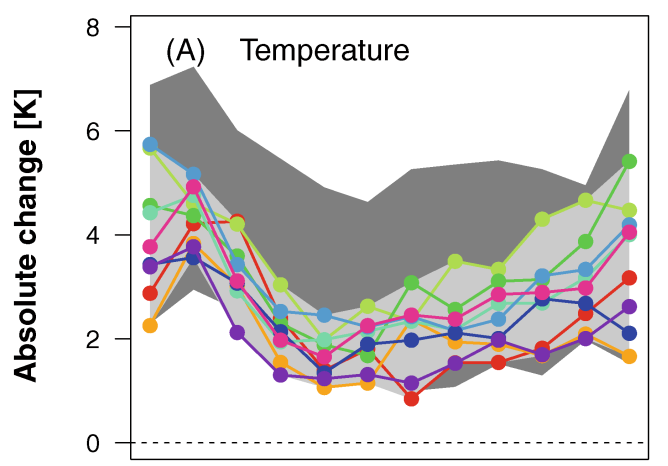

(B) Precipitation

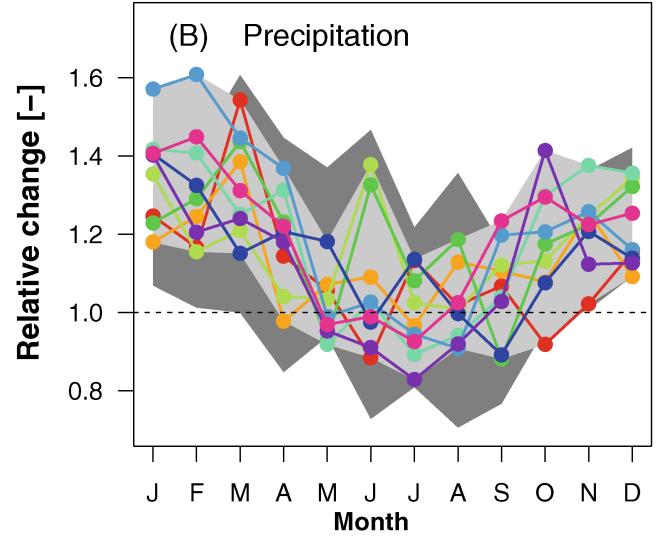

- CS1: RCA3 BCM A1B 50km

- CS2: RCA3_CCSM3_A1B_50km

- CS3: RCA3_HADCM3Q0_A1B_50km

- CS4: RCA3_IPSL_A1B_50km

- CS5: RCA3_ECHAM5_A1B_1_50km

- CS6: RCA3_ECHAM5_A1B_2_50km

- CS7: RCA3_ECHAM5_A1B_3_50km

- CS8: RCA3 ECHAM5 B1 1 $50 \mathrm{~km}$

- CS9: RCA3_ECHAM5_A2_1_50km

Fig. 1. Monthly change factors for (A) temperature and (B) precipitation derived from the nine different climate scenarios (see Table 2). The dark-grey background area represents the spread in the change factors for southern Sweden derived from an ensemble of 23 different GCMs (taken from Lind and Kjellström, 2008).

Kendall's non-parametric $W$ statistic (also called Kendall's coefficient of concordance) was used to evaluate the consistency of the response of the different parameter sets to climate change as projected by the different climate scenarios. For each of the acceptable parameterizations of the pesticide fate model, the simulated pesticide losses obtained with the different climate scenarios were first ranked $^{2}$, and then Kendall's $W$ was calculated to test whether this ranking was similar for the different parameterizations. Kendall's $W$ ranges from 0 (no agreement

\footnotetext{
${ }^{2}$ Rank 1 was given to the climate scenario producing the highest leaching losses within a particular parameterization of the pesticide fate model, and rank 9 to the climate scenario producing the lowest leaching losses.
}
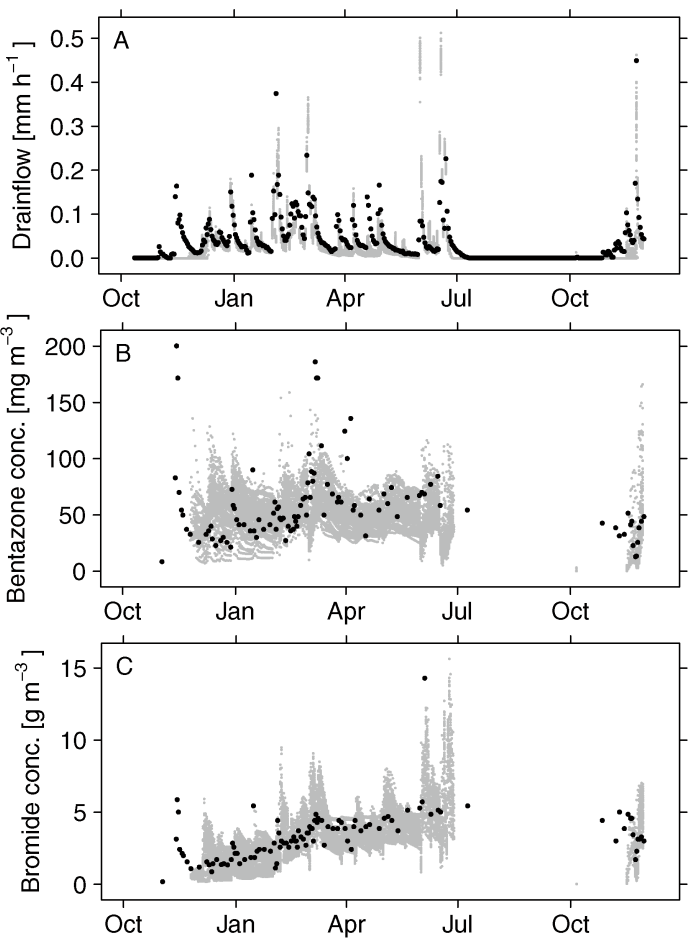

Fig. 2. Comparison between measurements (black) and the simulation results of all 56 acceptable parameter sets (grey) for (A) drain flow, (B) bentazone and (C) bromide concentrations in the drain flow.

between the ranks of the climate scenarios) to 1 (complete agreement). No agreement means total randomness of the response to different climate scenarios, whereas complete agreement means that the response of the pesticide model to changed climate was robust and consistent irrespective of the specific parameterization of the pesticide fate model. Thus, the larger the value of $W$, the stronger the role of climate input uncertainty compared to the parameter uncertainty of the pesticide fate model.

\section{Results and discussion}

\subsection{Calibration}

Model calibration resulted in 56 different parameter sets that were able to satisfactorily describe drain flow, water contents, and bentazone and bromide concentration in drain flow and soil. A visual depiction of the quality of the calibration results for the drain flow data is provided in Fig. 2. The posterior parameter values are presented as histograms in Fig. 3, with the $x$ axes marking the prior parameter uncertainty ranges. Most of the parameters were quite well constrained, especially for the topsoil $\left(K_{b}, d\right.$ and DT50, see Fig. 3a, c, and g). For $K_{\mathrm{oc}}$ in topsoil, the results seem to suggest some degree of equifinality (Fig. 3e). However, this 

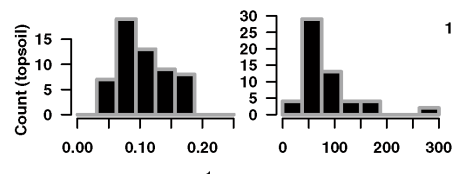

(A) $\mathrm{K}_{\mathrm{b}}\left[\mathrm{mm} \mathrm{h}^{-1}\right.$ (C) $\mathrm{d}[\mathrm{mm}]$

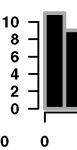

(E) $\mathrm{K}_{\mathrm{oc}}\left[\mathrm{cm}^{3} \mathrm{~g}^{-1}\right]$
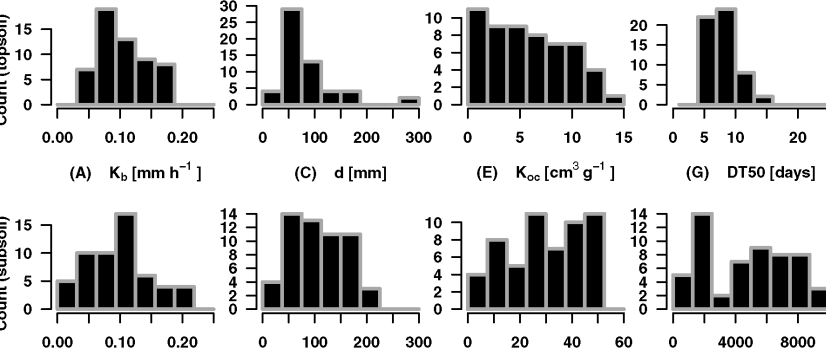

(D) $\mathrm{d}[\mathrm{mm}]$
(G) DT50 [days]

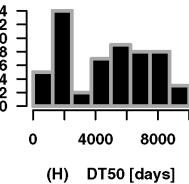

Fig. 3. Histograms with the posterior distributions of the eight different parameters included in the calibration step: saturated matrix hydraulic conductivity $\left(K_{b}\right)$, diffusion path-length $(d)$, soil organic carbon partitioning coefficient $\left(K_{\mathrm{oc}}\right)$ and the degradation half-life time (DT50). The range of values on the $x$ axis denote the prior range used for the different parameters. The total number of counts is 56 in all cases.

is because quite narrow prior uncertainty bounds were set for this parameter based on the previous simulations run by Steffens et al. (2013). Calibrated subsoil $K_{\text {oc }}$ values were always (with one exception) larger than the corresponding topsoil values, which shows the importance of inorganic soil constituents for sorption when the organic carbon content is low (Ghafoor et al., 2013). The slow degradation rates (i.e. high DT50 values) in the subsoil (Fig. 3h) agree well with the results of batch experiments carried out on samples from the same soil (Bergström et al., 1994). The measured total pesticide loss to drains was $8.5 \%$ of the applied amount, while simulated total losses for the calibration period varied between 3.1 and $6.2 \%$. This discrepancy was probably due to the inability of the model to simulate the first peak of pesticide leaching after application (see Fig. 2), which might be due to a lack of measurements below one metre depth, which presumably led to erroneous initial moisture conditions (especially regarding the initial depth of the ground water table in the model simulations).

\subsection{Pesticide leaching losses}

Simulated pesticide leaching losses under present and future climate conditions based on the 56 acceptable parameterizations of the MACRO model are summarized as cumulative distribution functions for all pesticide application scenarios in Fig. 4. The response of pesticide leaching to the different climate scenarios is denoted by the separate curves, which are also aggregated to a cumulative distribution function for the ensemble prediction. As expected, predicted leaching was highest for weakly, followed by moderately and strongly sorbed compounds. Pesticide leaching was generally higher for autumn applications than for spring applications, especially for moderately and strongly sorbed compounds. The climate uncertainty approximated by the variation in simulated pesticide losses for the different cli-
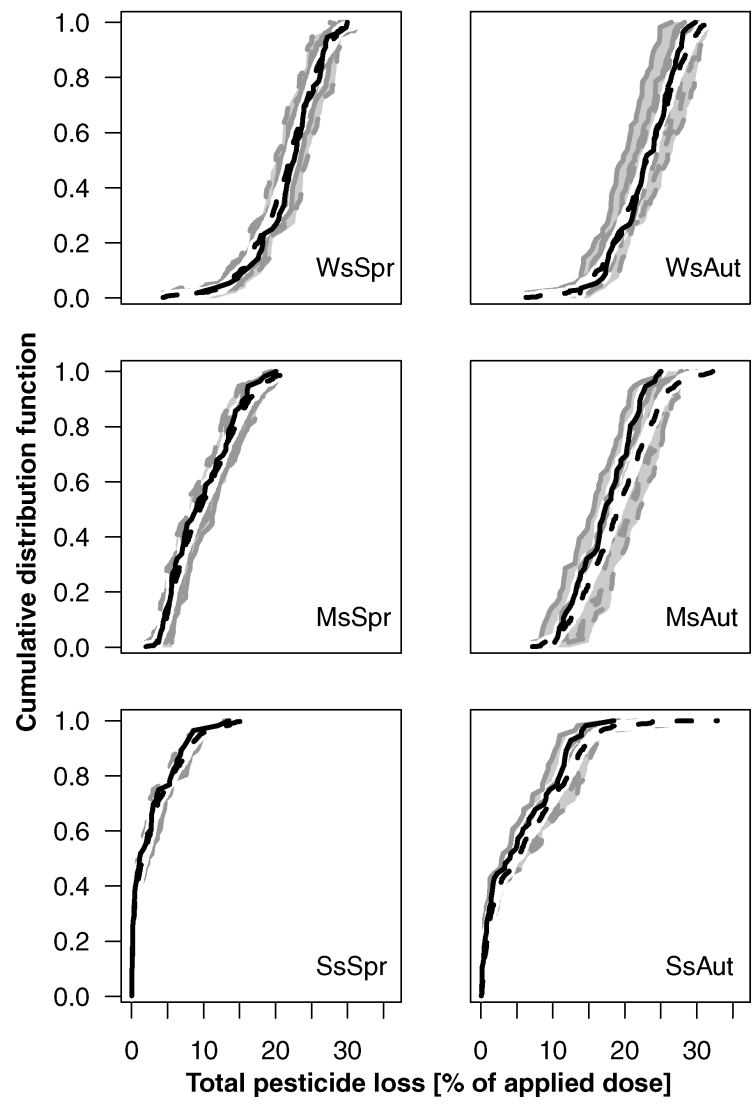

Fig. 4. Cumulative distribution functions of simulated pesticide losses for present (black solid) and future (grey lines) climate conditions based on nine different climate scenarios and 56 different parameterizations of the pesticide fate model. The aggregated ensemble predictions for the future are shown as black dashed lines for each of the pesticide application scenarios (abbreviations according to Table 3).

mate scenarios was also larger for autumn applications than for spring application, and decreased from weakly to strongly sorbed pesticides.

\subsection{Predicted changes in pesticide leaching losses}

Both the magnitude and the direction of predicted change in pesticide leaching from present to future (i.e. whether leaching increased or decreased) depended strongly on the particular climate scenario. This can be seen in Fig. 4, which shows absolute leaching losses, and in Fig. 5, in which the changes are explicitly plotted. For all pesticide application scenarios, there was at least one climate scenario that simulated an opposite direction of change in pesticide leaching compared to the other climate scenarios. The interplay of changes in temperature and precipitation throughout the year and the partly counteracting effects these variables have on the leaching of pesticides make a clear analysis of the causes of these differences very difficult. However, projections of autumn 

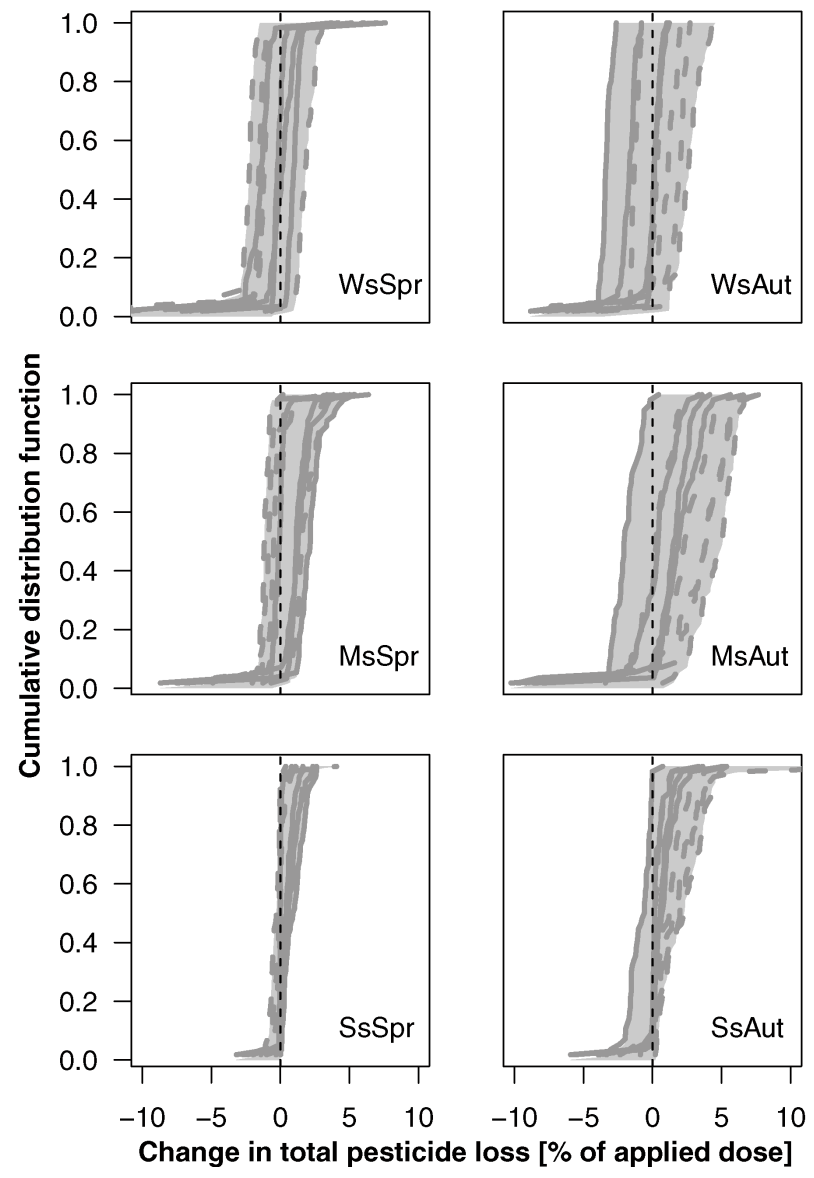

Fig. 5. Cumulative distribution functions for the predicted changes in pesticide leaching losses for the different climate scenarios (grey lines) as generated by 56 different parameterizations of the pesticide fate model. The pesticide application scenarios are abbreviated according to Table 3 . The black dashed line represents a zero change in pesticide loss.

precipitation could be identified as one important reason. For example, in all autumn pesticide application scenarios, the climate scenario CS1 (RCA3-BCM-A1B) simulated reduced pesticide leaching in the future compared to the present. This is the only climate scenario that projected reduced precipitation in October and negligible changes in November (Fig. 1), which demonstrates the importance of the projections of autumn precipitation for predicting pesticide leaching. This has significant implications for predictions of overall leaching risks that also consider the likely indirect effects of climate change, such as more autumn-sown crops and consequently more frequent application of pesticides in autumn. These potential indirect effects will be assessed in future studies.

For all pesticide application scenarios, the 5th and 95th percentiles of the changes in pesticide leaching ${ }^{3}$ included

\footnotetext{
${ }^{3}$ Here expressed as the smallest 5 th and largest 95 th percentile of the changes in pesticide leaching as simulated with all climate scenarios.
}

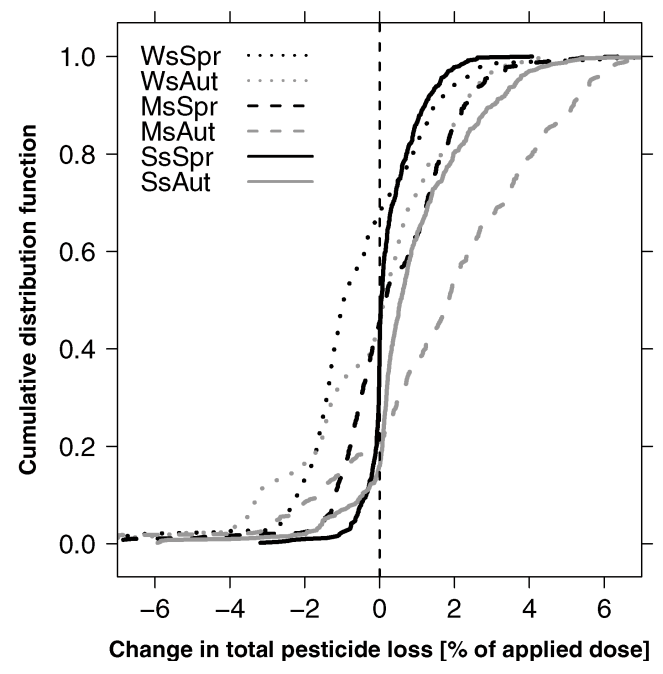

Fig. 6. Cumulative distribution functions of the ensemble predictions of the changes in pesticide leaching losses from present to future for the six pesticide application scenarios (as in Table 3). Each curve combines all 56 acceptable parameterizations of the pesticide fate model and the nine different climate scenarios. Spring applications are represented with black lines and autumn applications with grey lines. Dotted lines represent weakly sorbed pesticides; dashed lines represent moderately sorbed pesticides; solid lines represent strongly sorbed pesticides.

zero and ranged between -4.3 to $+6.5 \%$ of the applied dose (see Fig. 5). Thus, a consistent direction of change could not be identified for any pesticide application scenario, when taking into account the variation in the response of pesticide leaching to the whole ensemble of climate scenarios. This demonstrates the necessity of applying an ensemble of different climate scenarios in order to avoid biased conclusions and over-confidence in predicting the response of pesticide losses to climate change.

Ensemble modelling has been widely applied within climate sciences, and several studies have demonstrated that the mean of the climate model ensemble is the best estimate of the observations (Christensen et al., 2007; van der Linden and Mitchell, 2009; Kjellström et al., 2011). In hydrological impact studies, it has been shown that the use of an ensemble of climate models as input to hydrological models gives more appropriate results and should be preferred to the use of a single climate scenario (Teutschbein and Seibert, 2010, 2012; Dobler et al., 2012). Based on these ideas, the ensemble prediction for future pesticide losses presented as cumulative distributions (Fig. 4) could be considered a robust estimate for pesticide leaching under future climate conditions. For all spring application scenarios, as well as for the autumn application of the weakly sorbed pesticide, the ensemble prediction indicated very little change in a future climate compared to the present. However, in the case of autumn applications of moderately and strongly sorbed compounds, the ensemble predictions suggested increased pesticide losses in 


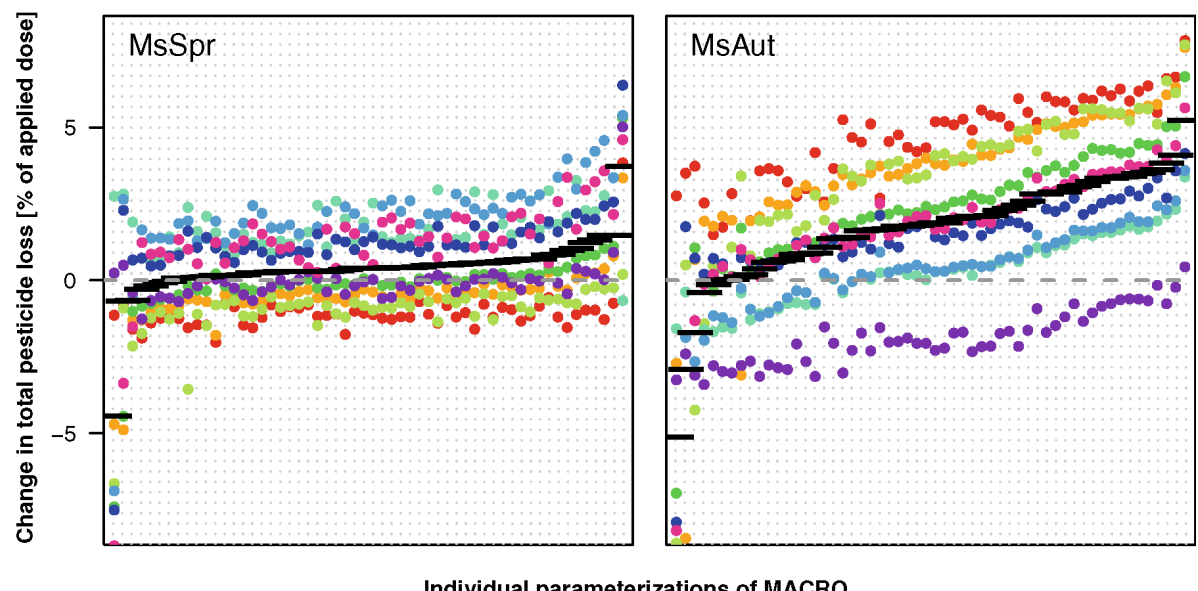

Fig. 7. Changes in pesticide leaching loss for the moderately sorbed pesticide applied in spring (MsSpr) and autumn (MsAut). The different coloured dots mark the different climate scenarios (same colour code as Fig. 1), the black lines denote the ensemble mean of the different climate scenarios for each parameterization ( $x$ axes) and the grey dashed line marks the zero line, which denotes no change between present and future leaching.

a future climate. This reflects the relatively larger importance of increased winter precipitation for autumn applications and the balancing or competitive effect of higher temperatures on degradation for compounds applied in spring (see also Steffens et al., 2013).

An ensemble prediction can also be made based on the calculated changes in pesticide leaching losses. These ensemble predictions of all 56 acceptable parameter sets and climate scenarios are presented as cumulative distribution functions for each pesticide application scenario in Fig. 6. For the weakly sorbed pesticide applied in spring (WsSpr), the ensemble indicated a $70 \%$ probability of reduced or unchanged pesticide losses in a future climate. For moderately and strongly sorbed pesticides applied in spring (MsSpr and SsSpr) and for the weakly sorbed pesticide applied in autumn (WsAut), the probability of increased or reduced losses were similar (i.e. $50 \%$ ). However, for moderately and strongly sorbed pesticides applied in autumn (MsAut and SsAut), the probability of increased leaching in a future climate was about $80 \%$ (Fig. 6). Thus, considering the overall result of the complete ensemble based on the available climate scenarios and parameterizations allowed for a probabilistic assessment of trends and direction of changes in pesticide leaching under climate change. This contributes to more robust and balanced conclusions regarding the potential impact of climate change on the risk of environmental pollution by pesticides.

\subsection{Parameter vs. climate input uncertainty}

The parameter uncertainty was represented in our study by the range of predictions of 56 acceptable parameterizations of the pesticide fate model. The effects of parameter uncertainty were rather high in all pesticide application scenarios for actual losses of pesticides under present and future climate conditions (Fig. 4). For absolute losses, the effects of uncertainty in the climate data, which are represented by the variation in simulation results for different climate scenarios, were smaller than the effects of parameter uncertainty. However, a consideration of the predictions of changes of pesticide losses from present to future (Fig. 5) suggests the opposite conclusion: the steep slopes indicate small effects of parameter uncertainty, while the differences between the climate scenarios were relatively more pronounced. These visual impressions were supported by the statistical indices we calculated (Table 3): the fraction of the parameter uncertainty in relation to the total uncertainty for absolute values of pesticide leaching losses $\left(F_{\mathrm{PU}_{\mathrm{abs}}}\right)$ was $85-98 \%$, which clearly demonstrated the dominance of parameter uncertainty. However, for the predicted changes of pesticide losses, the corresponding $F_{\mathrm{PU}_{\Delta}}$ values were much smaller, with values between 35 and $55 \%$ for weakly and moderately sorbed compounds and nearly $70 \%$ for the strongly sorbed pesticide. It can be noted that these values overestimate the pure parameter uncertainty, since the GLUE method maps all the different sources of uncertainty (e.g. forcing and model structure) onto the parameter space (Beven, 2006; Vrugt et al., 2009). However, the remaining fraction of the total uncertainty can be attributed exclusively to the climate input uncertainty, which is therefore rather high for weakly and moderately sorbed compounds (45 to $65 \%$ ). For strongly sorbed compounds, climate uncertainty plays a smaller role, contributing to 30 to $35 \%$ of the total uncertainty.

The consistency in the simulation results between different parameterizations of the pesticide fate model is one aspect that influences the relative importance of different sources of uncertainty. As an example, Fig. 7 visualizes the results of individual parameter sets for simulated changes in losses 
of the moderately sorbed pesticide applied in spring and autumn (MsSpr, MsAut). The results for each climate scenario are shown as coloured dots and the mean predictions of the ensemble of climate scenarios are marked with thick black lines. The ensemble means are rather similar in the different parameterizations in the case of spring application, but differ more between different parameterizations after autumn application. The results of the Kruskal-Wallis test (a nonparametric analysis of variance) for all pesticide scenarios support the visual impression of Fig. 7 and the conclusions drawn from the evaluation of the $F_{\mathrm{PU}}$ values; the mean values for changes in pesticide losses did not vary significantly between different parameterizations for the weakly sorbed pesticides irrespective of the application timing, and for moderately and strongly sorbed pesticides applied in spring (Table 3). Thus, for these pesticide application scenarios, the use of only one parameter set in combination with an ensemble of climate scenarios to estimate mean changes in pesticide leaching would be justified. For moderately and strongly sorbed pesticides applied in autumn, the KruskalWallis test showed significant differences among parameter sets (Table 3), and the use of an ensemble of parameterizations would be recommended. In the case of absolute leaching losses, the analysis of variance showed significant differences among parameter sets for all pesticide application scenarios (not shown).

The rank order of the simulated leaching losses forced by the nine climate scenarios differed between the pesticide application scenarios because the interplay of climate variables affected pesticide leaching in different ways mainly depending on the period of pesticide application (see Fig. 7), but also on the properties of the pesticide. However, the ranking was approximately consistent within a given pesticide application scenario (see Fig. 7), as Kendall's $W$ test gave values between 0.85 and 0.91 for all pesticide application scenarios (Table 3). This illustrates that the response of the pesticide fate model to changes in climate projected by the climate scenarios was similar and highly systematic for the different parameterizations of the pesticide fate model. Notably, this was even true for cases where the ensemble mean outputs varied significantly between parameter sets (MsAut and SsAut).

Taken together, these results strongly support the conclusion that although the effect of parameter uncertainty is large for simulated absolute pesticide losses, it is less significant in relation to climate uncertainty for predictions of changes of pesticide leaching in a future climate. Thus, our study gives some support to the findings of Dobler et al. (2012), which indicate that parameter uncertainty is less important than climate uncertainty. Furthermore, we might have underestimated the effect of climate uncertainty as we only included a limited number of climate scenarios in our study. As seen in Fig. 1, a larger ensemble often shows larger variation in projected climate changes, which is likely to result in a larger spread of pesticide losses. Our study clearly emphasized the necessity of applying an ensemble of climate scenarios in climate change impact assessments to account for the uncertainty in climate projections (see e.g. Teutschbein and Seibert, 2010).

\section{Concluding remarks}

From this study, we conclude that (1) climate input uncertainty is important and should be accounted for by applying an ensemble of possible climate scenarios; (2) a deterministic approach based on one acceptable parameterization of the impact model seems sufficient if the focus of the analysis is on assessing average changes in pesticide leaching between present and future, at least for many scenarios of interest (mobile or spring applied compounds); (3) for probabilistic assessments of changes in pesticide leaching, as much information as possible should be included in the analysis, i.e. ensembles of both parameterizations and climate scenarios; this will increase the robustness of the results and confidence in the predictions of directions and trends.

We assessed the role of uncertainties in predictions of pesticide leaching under present climate conditions and conditions for the end of the 21st century for the particular case of a well-structured clay soil in south-western Sweden. Since projections for future climate conditions vary locally and each soil requires individual parameterization, our results may not be transferable to other locations and sites. However, it seems rather likely that the effect of parameter uncertainty would be less important in non-structured soils without macropore flow, which would further strengthen our main results and recommendations. The choice of another downscaling approach, additional bias corrections or larger ensembles of climate scenarios might also affect the extent of the uncertainty arising from the climate projections as well as the predicted directions and especially magnitudes of changes in pesticide leaching losses. However, this should not change the general conclusion that the parameterization of the pesticide fate model is less important than the uncertainty in future climate projections.

Acknowledgements. This project was funded by the Swedish Farmers' Foundation for Agricultural Research (SLF). We thank Barry Broman at the Swedish Meteorological and Hydrological Institute for extracting the climate model projections, and Mick Whelan and an anonymous reviewer for their valuable comments.

Edited by: P. Grathwohl 


\section{References}

Anandhi, A., Frei, A., Pierson, D. C., Schneiderman, E. M., Zion, M. S., Lounsbury, D., and Matonse, A. H.: Examination of change factor methodologies for climate change impact assessment, Water Resour. Res., 47, W03501, doi:10.1029/2010WR009104, 2011.

Bengtsson, L.: The global atmospheric water cycle, Environ. Res. Lett., 5, 025002, doi:10.1088/1748-9326/5/2/025002, 2010.

Bergström, L., Jarvis, N. J., and Stenström, J.: Pesticide leaching data to validate simulation-models for registration purposes, J. Environ. Sci. Heal. A, 29, 1073-1104, 1994.

Beulke, S., Brown, C. D., Fryer, C. J., and Walker, A.: Lysimeter study to investigate the effect of rainfall patterns on leaching of isoproturon, Pest Manag. Sci., 58, 45-53, doi:10.1002/ps.419, 2002

Beulke, S., Boxall, A. B. A., Brown, C. D., Thomas, M., and Falloon, P.: Impacts of climate change on pesticide transport to groundwater and surface water, in: Environmental Fate and Ecological Effects, edited by: Del Re, A. A. M., Capri, E., Fraoulis, G., and Trevisan, M., XIII Symposium Pesticide Chemistry, Piacenza, Italy, 444-451, 2007.

Beven, K.: A manifesto for the equifinality thesis, J. Hydrol., 320, 18-36, doi:10.1016/j.jhydrol.2005.07.007, 2006.

Beven, K. and Binley, A.: The future of distributed models: model calibration and uncertainty prediction, Hydrol. Process., 6, 279298, doi:10.1002/hyp.3360060305, 1992.

Bleck, R. and Rooth, C. and Hu, D. and Smith, L. T.: Salinity-driven thermocline transients in a wind-forced and thermohaline-forced isopycnic coordinate model of the NorthAtlantic, J. Phys. Oceanogr., 22, 1486-1505, doi:10.1175/15200485(1992)022<1486:SDTTIA>2.0.CO;2, 1992.

Bloomfield, J. P., Williams, R. J., Gooddy, D. C., Cape, J. N., and Guha, P.: Impacts of climate change on the fate and behaviour of pesticides in surface and groundwater - a UK perspective, Sci. Total Environ., 369, 163-177, doi:10.1016/j.scitotenv.2006.05.019, 2006.

Boesten, J. J. T. I. and Van der Linden, A. M. A.: Modeling the influence of sorption and transformation on pesticide leaching and persistence, J. Environ. Qual., 20, 425-435, 1991.

Boesten, J. J. T. I.:Sensitivity analysis of a mathematical model for pesticide leaching to groundwater, Pestic. Sci., 31, 375-388, 1991.

Brücher, J. and Bergström, L.: Temperature dependence of linuron sorption to three different agricultural soils, J. Environ. Qual., 26, 1327-1335, 1997.

Capel, P. D., Larson, S. J., and Winterstein, T. A.: The behaviour of 39 pesticides in surface waters as a function of scale, Hydrol. Process., 15, 1251-1269, doi:10.1002/hyp.212, 2001.

Chen, J., Brissette, F. P., and Leconte, R.: Uncertainty of downscaling method in quantifying the impact of climate change on hydrology, J. Hydrol., 401, 190-202, doi:10.1016/j.jhydrol.2011.02.020, 2011.

Christensen, J. H., Carter, T. R., Rummukainen, M., and Amanatidis, G.: Evaluating the performance and utility of regional climate models: the PRUDENCE project, Climatic Change, 81, 16, doi:10.1007/s10584-006-9211-6, 2007.
Collins, W. D., Bitz, C. M., Blackmon, M. L., Bonan, Gordon B., Bretherton, C. S., Carton, J. A., Chang, P., Doney, S. C., Hack, J. J., Henderson, T. B., Kiehl, J. T. and Large, W. G., McKenna, D. S., Santer, B. D., and Smith, R. D.: The Community Climate System Model version 3 (CCSM3), J. Climate, 19, 2122-2143, doi:10.1175/JCLI3761.1, 2006.

Delpla, I., Jung, A.-V., Baures, E., Clement, M., and Thomas, O.: Impacts of climate change on surface water quality in relation to drinking water production, Environ. Int., 35, 1225-1233, doi:10.1016/j.envint.2009.07.001, 2009.

Déqué, M., Dreveton, C., Braun, A., and Cariolle, D: The ARPEGE/IFS atmosphere model - a contribution to the French community climate modeling, Clim. Dynam., 10, 249-266, 1994.

Dobler, C., Hagemann, S., Wilby, R. L., and Stötter, J.: Quantifying different sources of uncertainty in hydrological projections in an Alpine watershed, Hydrol. Earth Syst. Sci., 16, 4343-4360, doi:10.5194/hess-16-4343-2012, 2012.

Dubus, I. G. and Brown, C. D.: Sensitivity and first-step uncertainty analyses for the preferential flow model MACRO, J. Environ. Qual., 31, 227-240, 2002.

Dubus, I. G., Brown, C. D., and Beulke, S.: Sources of uncertainty in pesticide fate modelling, Sci. Total Environ., 317, 5372, doi:10.1016/S0048-9697(03)00362-0, 2003.

Dubus, I. G., Brown, C. D., and Beulke, S.: Sensitivity analyses for four pesticide leaching models, Pest Manag. Sci., 59, 962-982, doi:10.1002/ps.723, 2003.

FOCUS: FOCUS groundwater scenarios in the EU review of active substances, Report of the FOCUS Groundwater Scenarios Workgroup, EC Document Reference SANCO/321/2000 rev.2, 202 pp., 2000.

FOCUS: FOCUS Surface Water Scenarios in the EU Evaluation Process under 91/414/EEC, Report of the FOCUS Working Group on Surface Water Scenarios, EC Document Reference SANCO/4802/2001-rev.2, 245 pp., 2001.

Fowler, H. J., Blenkisop, S., and Tebaldi, C.: Review - linking climate change modelling to impacts studies: recent advances in downscaling techniques for hydrological modelling, Int. J. Climatol., 27, 1547-1578, doi:10.1002/joc.1556, 2007.

Gerke, H. H. and Van Genuchten, M. T.: Macroscopic representation of structural geometry for simulating water and solute movement in dual-porosity media, Adv. Water Resour., 19, 343-357, 1996.

Germann, P. F.: Kinematic wave approach to infiltration and drainage into and from soil macropores, T. ASAE, 28, 745-749, 1985.

Ghafoor, A., Jarvis, N. J., and Stenström, J.: Modelling pesticide sorption in the surface and subsurface soils of an agricultural catchment, Pest Manag. Sci., 69, 919-929, doi:10.1002/ps.3453, 2013.

Gordon, C., Cooper, C., Senior, C. A., Banks, H., Gregory, J. M., Johns, T. C., Mitchell, J. F. B., and Wood, R. A.: The simulation of SST, sea ice extents and ocean heat transports in a version of the Hadley Centre coupled model without flux adjustments, Clim. Dynam., 16, 147-168, doi:10.1007/s003820050010, 2000. 
Graaf, S., Adielsson, S., and Kreuger, J.: Resultat från miljöövervakningen av bekämpningsmedel (växtskyddsmedel) Årssammanställning 2009, Ekohydrologi 120 version 2, Department of Soil and Environment, Swedish University of Agricultural Sciences, Uppsala, Sweden, 2010.

Graaf, S., Adielsson, S., and Kreuger, J.: Resultat från miljöövervakningen av bekämpningsmedel (växtskyddsmedel) Årssammanställning 2010, Ekohydrologi 128, Department of Soil and Environment, Swedish University of Agricultural Sciences, Uppsala, Sweden, 2011.

Graham, L. P., Hagemann, S., Jaun, S., and Beniston, M.: On interpreting hydrological change from regional climate models, Climatic Change, 81, 97-122, doi:10.1007/s10584-006-9217-0, 2007.

Hawkins, E. and Sutton, R.: The potential to narrow uncertainty in regional climate predictions, B. Am. Meteorol. Soc., 90, 10951107, doi:10.1175/2009BAMS2607.1, 2009.

Holvoet, K. M. A., Seuntjens, P., and Vanrolleghem, P. A.: Monitoring and modeling pesticide fate in surface waters at the catchment scale, Ecol. Model., 209, 53-64, doi:10.1016/j.ecolmodel.2007.07.030, 2007.

Hourdin, F., Musat, I., Bony, S., Braconnot, P., Codron, F., Dufresne, J.-L., Fairhead, L., Filiberti, M.-A., Friedlingstein, P., Grandpeix, J.-Y., Krinner, G., LeVan, P., Li, Z.-X., and Lott, F.: The LMDZ4 general circulation model: climate performance and sensitivity to parametrized physics with emphasis on tropical convection, Clim. Dynam., 27, 787-813, doi:10.1007/s00382006-0158-0, 2006.

Jarvis, N. J.: A simple empirical model of root water uptake, J. Hydrol., 107, 57-72, 1989.

Jarvis, N. J.: The MACRO model (version 4.2), Tech. rep., Swedish University of Agricultural Sciences, Department of Soil Science, Uppsala, Sweden, 1994.

Jarvis, N. J.: Modelling the impact of preferential flow on non-point source pollution, in: Physical Nonequilibrium in Soils: Modeling and Application, edited by: Selim, H. M. and Ma, L., Ann Arbor Press, Chelsea, Michigan, 195-221, 1998.

Johnsson, H., Larsson, M., Lindsjö, A., Mårtensson, K., Persson, K., and Torstensson, G.: Läckage av näringsämnen från svensk åkermark - Beräkningar av normalläckage av kväve och fosfor för 1995 och 2005, Rapport 5832, Naturvårdsverket, Stockholm, Sweden, 2008.

Jungclaus, J. H., Keenlyside, N., Botzet, M., Haak, H., Luo, J.J., Latif, M., Marotzke, J., Mikolajewicz, U., and Roeckner, E.: Ocean circulation and tropical variability in the coupled model ECHAM5/MPI-OM, J. Climate, 19, 3952-3972, doi:10.1175/JCLI3827.1, 2006.

Kattwinkel, M., Kühne, J.-V., Foit, K., and Liess, M.: Climate change, agricultural insecticide exposure, and risk for freshwater communities, Ecol. Appl., 21, 2068-2081, doi:10.1890/101993.1, 2011.

Kjellström, E., Nikulin, G., Hansson, U., Strandberg, G., and Ullerstig, A.: 21st century changes in the European climate: uncertainties derived from an ensemble of regional climate model simulations, Tellus, 63, 24-40, doi:10.1111/j.1600-0870.2010.00475.x, 2011.
Lamon, L., Dalla Valle, M., Critto, A., and Marcomini, A.: Introducing an integrated climate change perspective in POPs modelling, monitoring and regulation, Environ. Pollut., 157, 19711980, doi:10.1016/j.envpol.2009.02.016, 2009.

Larsbo, M., Roulier, S., Stenemo, F., Kasteel, R., and Jarvis, N. J.: An improved dual-permeability model of water flow and solute transport in the vadose zone, Vadose Zone J., 4, 398-406, doi:10.2136/vzj2004.0137, 2005.

Larsbo, M. and Jarvis, N. J.: Simulating solute transport in a structured field soil: Uncertainty in parameter identification and predictions, J. Environ. Qual., 34, 621-634, 2005.

Larsson, M. H. and Jarvis, N. J.: Evaluation of a dual-porosity model to predict field-scale solute transport in a macroporous soil, J. Hydrol., 215, 153-171, doi:10.1016/S00221694(98)00267-4, 1999.

Ledbetter, R., Prudhomme, C., and Arnell, N.: A method for incorporating climate variability in climate change impact assessments: sensitivity of river flows in the Eden catchment to precipitation scenarios, Climatic Change, 113, 803-823, doi:10.1007/s10584-011-0386-0, 2012.

Lewan, E., Kreuger, J., and Jarvis, N. J.: Implications of precipitation patterns and antecedent soil water content for leaching of pesticides from arable land, Agr. Water Manage., 96, 1633-1640, doi:10.1016/j.agwat.2009.06.006, 2009.

Lind, P. and Kjellström, E.: Temperature and precipitation changes in Sweden; a wide range of model-based projections for the 21st century, Reports Meteorology and Climatology, SMHI, Norrköping, Sweden, 113, 50 pp., 2008.

Roeckner, E., Brokopf, R., Esch, M., Giorgetta, M., Hagemann, S., Kornblueh, L., Manzini, E., Schlese, U., and Schulzweida, U.: Sensitivity of simulated climate to horizontal and vertical resolution in the ECHAM5 atmosphere model, J. Climate, 19, 37713791, doi:10.1175/JCLI3824.1, 2006.

Nash, J. E. and Sutcliffe, J. V.: River flow forecasting through conceptual models, Part I - A discussion of principles, J. Hydrol., 10, 282-290, doi:10.1016/0022-1694(70)90255-6, 1970.

Nolan, B. T., Dubus, I. G., Surdyk, N., Fowler, H. J., Burton, A., Hollis, J. M., Reichenberger, S., and Jarvis, N. J.: Identification of key climatic factors regulating the transport of pesticides in leaching and to tile drains, Pest Manag. Sci., 64, 933-944, doi:10.1002/ps.1587, 2008.

Noyes, P. D., McElwee, M. K., Miller, H. D., Clark, B. W., Van Tiem, L. A., Walcott, K. C., Erwin, K. N., and Levin, E. D.: The toxicology of climate change: environmental contaminants in a warming world, Environ. Int., 35, 971-986, 2009.

Olsson, J.: Evaluation of a scaling cascade model for temporal rain- fall disaggregation, Hydrol. Earth Syst. Sci., 2, 19-30, doi:10.5194/hess-2-19-1998, 1998.

Prudhomme, C., Wilby, R. L., Crooks, S., Kay, A. L., and Reynard, N. S.: Scenario-neutral approach to climate change impact studies: application to flood risk, J. Hydrol., 390, 198-209, doi:10.1016/j.jhydrol.2010.06.043, 2010.

Rummukainen, M.: State-of-the-art with regional climate models, WIRE Climatic Change, 1, 82-96, doi:10.1002/wcc.8, 2010.

Samuelsson, P., Jones, C. G., Willén, U., Ullerstig, A., Gollvik, S., Hansson, U., Jansson, C., Kjellström, E., Nikulin, G., and Wyser, K.: The Rossby Centre Regional Climate model RCA3: model description and performance, Tellus A, 63, 4-23, doi:10.1111/j.1600-0870.2010.00478.x, 2011. 
Shariff, R. M. and Shareef, K. M.: Thermodynamic adsorption of herbicides on eight agricultural soils, International Journal of Scientific \& Engineering Research, 2, 238-245, 2011.

Steffens, K., Larsbo, M., Moeys, J., Jarvis, N., and Lewan, E.: Predicting pesticide leaching under climate change: importance of model structure and parameter uncertainty, Agr. Ecosyst. Environ., 172, 24-34, doi:10.1016/j.agee.2013.03.018, 2013.

ten Hulscher, T. E. M. and Cornelissen, G.: Effect of temperature on sorption equilibrium and sorption kinetics of organic micropollutants - a review, Chemosphere, 32, 609-626, doi:10.1016/00456535(95)00345-2, 1996.

Teutschbein, C. and Seibert, J.: Regional climate models for hydrological impact studies at the catchment scale: a review of recent modeling strategies, Geography Compass, 4, 834-860, doi:10.1111/j.1749-8198.2010.00357.x, 2010.

Teutschbein, C. and Seibert, J.: Bias correction of regional climate model simulations for hydrological climate-change impact studies: review and evaluation of different methods, J. Hydrol., 456457, 12-29, doi:10.1016/j.jhydrol.2012.05.052, 2012.

Teutschbein, C., Wetterhall, F., and Seibert, J.: Evaluation of different downscaling techniques for hydrological climate-change impact studies at the catchment scale, Clim. Dynam., 37, 20872105, doi:10.1007/s00382-010-0979-8, 2011.

van der Linden, P. and Mitchell, J. F. B.: ENSEMBLES: Climate change and its impacts: Summary of research and results from the ENSEMBLES project, Met Office Hadley Centre, Exeter, UK, 2009.
Vrugt, J. A., ter Braak, C. J. F., Gupta, H. V., and Robinson, B. A.: Equifinality of formal (DREAM) and informal (GLUE) Bayesian approaches in hydrologic modeling?, Stoch. Env. Res. Risk A., 23, 1011-1026, doi:10.1007/s00477-008-0274-y, 2009.

Walker, A.: A simulation model for prediction of herbicide persistence, J. Environ. Qual., 3, 396-401, 1974.

Whitehead, P. G., Wilby, R. L., Battarbee, R. W., Kernan, M., and Wade, A. J.: A review of the potential impacts of climate change on surface water quality, Hydrolog. Sci. J., 54, 101-123, doi:10.1623/hysj.54.1.101, 2009.

Wilby, R. L., Hay, L. E., Gutowski, W. J., Arritt, R. W., Takle, E. S., Pan, Z. T., Leavesley, G. H., and Clark, M. P.: Hydrological responses to dynamically and statistically downscaled climate model output, Geophys. Res. Lett., 27, 11991202, doi:10.1029/1999GL006078, 2000.

Wilby, R. L., Troni, J., Biot, Y., Tedd, L., Hewitson, B. C., Smith, D. M., and Sutton, R. T.: A review of climate risk information for adaptation and development planning, Int. J. Climatol., 29, 1193-1215, doi:10.1002/joc.1839, 2009.

Zhao, M., Held, I. M., Lin, S. J., and Vecchi, G. A.: Simulations of global hurricane climatology, interannual variability and response to global warming using a 50-km resolution GCM, J. Climate, 22, 6653-6678, doi:10.1175/2009JCLI3049.1, 2009. 